\title{
Identification Method for Evolution of Time Series with Poor Information Using Grey System Theory
}

\author{
Xintao Xia ${ }^{1}$, Yang $\mathrm{Lu}^{1}$, Tao $\mathrm{Ma}^{1} \&$ Long $\mathrm{Chen}^{1}$ \\ ${ }^{1}$ College of Mechatronical Engineering, Henan University of Science and Technology, Luoyang, China \\ Correspondence: Xintao Xia, 63\#, Xiyuan Campus, Henan University of Science and Technology, 48 Xiyuan \\ Road, Luoyang 471003, China. Tel: 86-379-6421-9460. E-mail: xiaxt1957@163.com,xiaxt@mail.haust.edu.cn
}

Received: April 9, 2012

doi:10.5539/mer.v2n1p71
Accepted: May 2, 2012 Online Published: May 24, 2012

URL: http://dx.doi.org/10.5539/mer.v2n1p71

\begin{abstract}
Based on the grey system theory, a new method is presented to identify evolution of time series with poor information. Via definition of the original state sequence and the evolution state sequence, the information element function along with the grey confidence level is introduced into the criterion for identification of the stability of time series. The simulation test of initial worn stages of a mechanical device shows that without any prior information of trends and functions, the method can effectively recognize and evaluate the state of evolution of time series. It follows that corresponding measures in a timely manner can be taken and serious accidents can be avoided.
\end{abstract}

Keywords: time series, evolution, stability, identification, grey system theory, poor information

\section{Introducation}

Process identification of time series is used widely in many fields, such as, natural world, environment, society, economy, national defense, industry, agriculture, geology, public health, and information (Eleni, 2008; Paulin, $2005 ; \mathrm{Li}, 2012$ ). Timely and scientifically recognizing the stability of evolution of events with characteristics of time series can contribute to effective precautions of serious accidents by taking appropriate measures, producing tremendous economic and social profits.

There are many methods to study time series at present (Eleni, 2008; Paulin \& Connely, 2005; Li \& Hu, 2012; Sheng, Zhao, Liu, \& Wang, 2012; Castro \& Azevedo, 2012; Chen, Hong, \& Tseng, 2012; Çoban, Büyüklü, \& Das, 2012; Ailliot \& Monbet, 2012; Khvorostovsky, 2012; Das \& Maitra, 2012). The models structured by available findings manly include wavelet neural network and catastrophe theory model, self-organization theory model, regression model, autoregressive regression model, piecewise linearization model, adaptive segmentation linearization model, predicted network model, interval number model, empirical mode decomposition and phase space reconstruction model, and similarity model. With the help of information that time series present, these models are effective under the condition of known trends and functions, such as, potential functions, wavelet basis functions, kernel functions, probability distribution functions, and piecewise linear functions.

With the rapid development of economy and science, information that time series displays is characterized by diversity and complexity and the feature of some information is unknown in advance. For example, trends and functions of many events have uncertainty, diversity, mutability, and nonmonotonicity (Eleni, 2008; Paulin et al., 2005; Sheng et al., 2012; Coban et al., 2012). The problem studied, in fact, belongs to the category of the information-poor system (Deng, 1989, 2002; Xia, Chen, Zhang, \& Yang, 2007; Xia \& Li, 2011; Xia \& Chen, 2011a). Poor information means incomplete information, such as, in system analysis, unknown trends and functions. This generates that statistical methods for time series analysis are faced with the flinty challenge. For this reason, the paper proposes a new method for identification of the stability of evolution of time series with poor information by means of the grey system theory (Deng, 1989, 2002; Xia et al., 2007, 2011, 2011a). The simulation test of initial worn stages of a mechanical device is conducted to verify effectiveness of the method proposed in the paper.

\section{Introduction to Grey System Theory}

In 1989, Prof. Deng Julong proposed the grey system theory (Deng, 1989) to research mainly the uncertainty systems with poor information. The systems can be divided into three types: the black system, the white system, 
and the grey system. The black system is not perceived one, the white system is perceived one, and the grey system is a partly perceived and unascertained system between the black and white systems (Xia, 2012).

The grey relational grade as a very important concept in the grey system theory is widely used in many fields of science and technology (Xia et al., 2007, 2011, 2011a; Jiang \& He, 2012; Wen, You, \& Lee, 2010; Sridhar, Narasimha Murthy, Pattar, Vishnu Mahesh, \& Krishna, 2012; Palanikumar, Latha, Senthilkumar, \& Davim, 2012). For example, it can be employed to evaluate the difference of the attributes of systems acoording to the geometry shape of data series outputted by these systems. The bigger the value the grey relational grade takes, the smaller the difference of the attributes of systems; or else, the bigger the difference.

Assume $t$ stands for time and $X_{i}$ for the $i$ th curve where $i=1,2,3$ is the sequence number. Figure 1 shows three time series expressed as the curves $X_{1}, X_{2}$, and $X_{3}$, respectively. According to the grey system theory, the grey relational grade of $X_{2}$ to $X_{1}$ is greater than that of $X_{3}$ to $X_{1}$ because the geometry shape of $X_{2}$ and $X_{1}$ is more similar than that of $X_{3}$ and $X_{1}$. This means that the difference between the attributes of $X_{1}$ and $X_{2}$ is smaller than that between the attributes of $X_{1}$ and $X_{3}$. Based on this, evolution of time series can be evaluates.

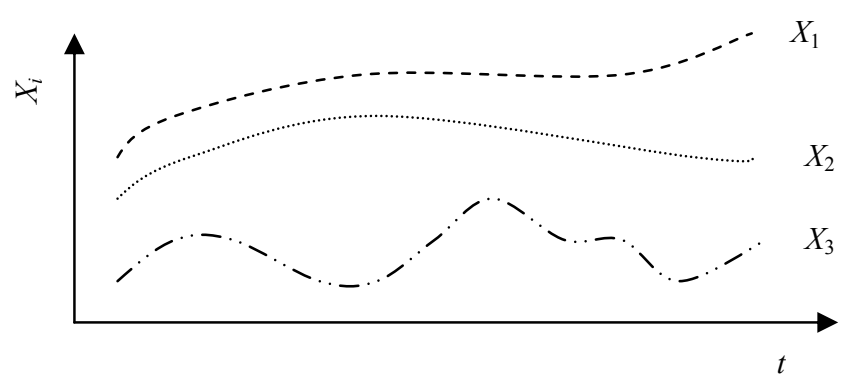

Figure 1. Similarity of curves

\section{Information Element Function Along with Grey Confidence Level}

In the process of evolution of an event studied, $n$ data are collected and then the time series $X$ can be obtained as

$$
X=(x(1), x(2), \ldots, x(i), \ldots, x(n))
$$

where $x(i)$ is the $i$ th datum in $X$ and $n$ is the number of the data in $X$.

The time series $X$ is divided into $m$ subseries, which are given by

$$
X_{w}=\left(x_{w}(1), x_{w}(2), \ldots, x_{w}(k), \ldots, x_{w}(K)\right) ; w=0,1,2, \ldots, m-1 ; k=1,2, \ldots, K ; K=n / m
$$

where $x_{w}(k)$ is the kth datum in $X_{w}$ and $K$ is the number of the data in $X_{w}$.

In equation (2), the first subseries is defined as the original state sequence $X_{0}$ and the others are defined as the evolution state sequence. The original state sequence $X_{0}$ is given by

$$
X_{0}=\left(x_{0}(1), x_{0}(2), \ldots, x_{0}(k), \ldots, x_{0}(K)\right)
$$

and the evolution state sequence $X_{j}$ is given by

$$
X_{j}=\left(x_{j}(1), x_{j}(2), \ldots, x_{j}(k), \ldots, x_{j}(K)\right) ; j=1,2, \ldots, m-1
$$

The reference sequence $X_{\mathrm{C}}$ is defined as

$$
X_{\mathrm{C}}=\left(x_{\mathrm{C}}(1), x_{\mathrm{C}}(2), \ldots x_{\mathrm{C}}(k), \ldots, x_{\mathrm{C}}(K)\right)=\left(x_{0}(1), x_{0}(1), \ldots, x_{0}(1), \ldots, x_{0}(1)\right)
$$

According to the grey system theory (Deng, 1989, 2002; Xia et al., 2007, 2011, 2011a), the grey relational grade of the original state sequence $X_{0}$ to the reference sequence $X_{\mathrm{C}}$ is given by

$$
\gamma_{0 \mathrm{C}}(\xi)=\frac{1}{K} \sum_{k=1}^{K} \frac{\min _{k}\left|x_{\mathrm{C}}(k)-x_{0}(k)\right|+\xi \max _{k}\left|x_{\mathrm{C}}(k)-x_{0}(k)\right|}{\left|x_{\mathrm{C}}(k)-x_{0}(k)\right|+\xi \max _{k}\left|x_{\mathrm{C}}(k)-x_{0}(k)\right|}
$$

and the grey relational grade of the evolution state sequence $X_{j}$ to the reference sequence $X_{\mathrm{C}}$ is given by 


$$
\gamma_{j \mathrm{C}}(\xi)=\frac{1}{K} \sum_{k=1}^{K} \frac{\min _{k}\left|x_{\mathrm{C}}(k)-x_{j}(k)\right|+\xi \max _{k}\left|x_{\mathrm{C}}(k)-x_{j}(k)\right|}{\left|x_{\mathrm{C}}(k)-x_{j}(k)\right|+\xi \max _{k}\left|x_{\mathrm{C}}(k)-x_{j}(k)\right|}
$$

According to the grey system theory (Xia et al., 2007, 2011, 2011a), the information element function is defined as

$$
r_{0 j}=\left\{\begin{aligned}
1-\frac{1}{\eta} \max _{\xi \rightarrow \xi^{*}}\left|\gamma_{0 \mathrm{C}}(\xi)-\gamma_{j \mathrm{C}}(\xi)\right| & ; \max _{\xi \rightarrow \xi^{*}}\left|\gamma_{0 \mathrm{C}}(\xi)-\gamma_{j \mathrm{C}}(\xi)\right| \in[0, \eta] \\
0 & ; \max _{\xi \rightarrow \xi^{*}}\left|\gamma_{0 \mathrm{C}}(\xi)-\gamma_{j \mathrm{C}}(\xi)\right| \in[\eta, 1]
\end{aligned}\right.
$$

where $r_{0 j}$ stands for the information element function of evolution of the time series, $\eta$ for the weight, $\xi$ for the distinguishing coefficient, and $\xi^{*}$ for the optimal distinguishing coefficient.

According to the grey system theory (Xia et al., 2007, 2011, 2011a), the grey confidence level is given by

$$
P_{0 j}=(1-0.5 \eta) \times 100 \%
$$

where $P_{0 j}$ is the grey confidence level.

Equation (8) is called the information element function along with the grey confidence level (viz., equation (9)), which can be used for identifying the stability of the time series.

\section{Criterion for Identifying Stability of Time Series}

Letting the information element function $r_{0 j}=0.5$, the criterion of the stability of time series is defined and shown in Table 1 by means of the least information principle (Deng, 2002) in the grey system theory and the little probability event principle (Xia et al, 2007) in the statistical theory and the information-poor theory.

Table 1. Criterion for identification of stability of time series

\begin{tabular}{llll}
\hline $\begin{array}{l}\text { Code of } \\
\text { grade }\end{array}$ & $\begin{array}{l}\text { Condition of grey confidence } \\
\text { level }\end{array}$ & Grade and stability of time series & $\begin{array}{l}\text { Possibility of potential } \\
\text { safety problem }\end{array}$ \\
\hline G1 & $P_{0 j} \in[99 \%, 100 \%]$ & Grade 1 and best stability & Smallest \\
G2 & $P_{0 j} \in[95 \%, 99 \%)$ & Grade 2 and better stability & Smaller \\
G3 & $P_{0 j} \in[90 \%, 95 \%)$ & Grade 3 and good stability & Small \\
G4 & $P_{0 j} \in[85 \%, 90 \%)$ & Grade 4 and bad stability & Large \\
G5 & $P_{0 j} \in[75 \%, 85 \%)$ & Grade 5 and worse stability & Larger \\
G6 & $P_{0 j} \in[0 \%, 75 \%)$ & Grade 6 and worst stability & Largest \\
\hline
\end{tabular}

\section{Simulation Test}

This is a simulative case of time series. In the process of monitoring of running state of a simulated mechanical device, an operating parameter is taken into account with the help of simulation of a time series that is in motion from initial worn stages to normal worn stages. Suppose the theoretical value of the operating parameter is zero.

The data of the operating parameter are collected seven times, one time every five days, and 400 data are obtained one time, thus the time series $X$ of size $n=2800$ is formed in the simulation test, as shown in Figure 2 .

Let $K=400$ and $m=7$, then seven subseries are structured. In Figure 1, the first interval of values the abscissa $k$ takes, viz., $[1,400]$, corresponds to the original state sequence $X_{0}$ and the other intervals of values the abscissa $k$ takes, viz., [401,800], [801,1200], [1201,1600], [1601,2000], [2001,2400], and [2401,2800], correspond to the evolution state sequences $X_{1}, X_{2}, \ldots, X_{5}$, and $X_{6}$, respectively.

Let the information element function $r_{0 j}=0.5$, then the grey confidence level $P_{0 j}$ can be calculated from equations (8) and (9) and the process of evolution of the operating parameter of the mechanical device can therefore be distinguished. The results are presented in Table 2 . 


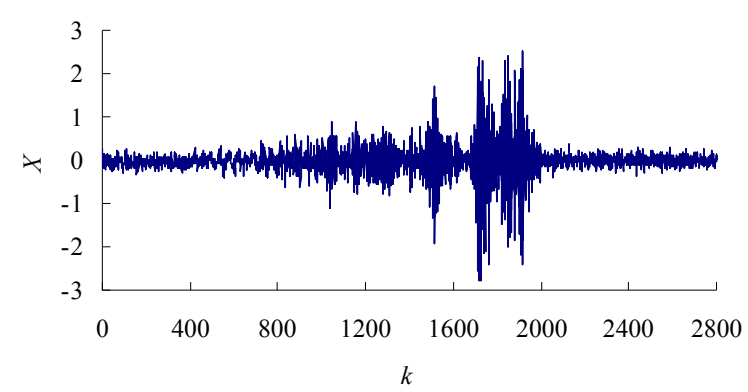

Figure 2. Time series of operating parameter of simulated mechanical device

It can be seen from Table 2 that the running state of the mechanical device is very stable for the evolution state sequences $X_{1}, X_{2}, X_{3}, X_{5}$, and $X_{6}$, because the grey confidence level $P_{0 j}$ takes values in the range from $94.05 \%$ to $96.77 \%$, which result from the stationary initial worn stage and normal worn stage; and the running state of the mechanical device is unstable for the evolution state sequences $X_{4}$, because the grey confidence level $P_{0 j}$ takes value $89.65 \%$, which results from the nonstationary initial worn stage.

Table 2. Identification result of running state of simulated mechanical device

\begin{tabular}{lllll}
\hline $\begin{array}{l}\text { Evolution state } \\
\text { sequence, } X_{j}\end{array}$ & $\begin{array}{l}\text { Grey confidence } \\
\text { level, } P_{0 j}\end{array}$ & Grade & Stability & $\begin{array}{l}\text { Running state of simulated } \\
\text { mechanical device }\end{array}$ \\
\hline$X_{1}$ & 95.96 & $\mathrm{G} 2$ & Better & Start of initial worn \\
$X_{2}$ & 94.05 & $\mathrm{G} 3$ & Good & Fluctuation of initial worn \\
$X_{3}$ & 96.77 & $\mathrm{G} 2$ & Better & Progress of initial worn \\
$X_{4}$ & 89.65 & $\mathrm{G} 4$ & Bad & Acme of initial worn \\
$X_{5}$ & 95.98 & $\mathrm{G} 2$ & Better & End of initial worn \\
$X_{6}$ & 96.65 & $\mathrm{G} 2$ & Better & Start of normal worn \\
\hline
\end{tabular}

As a result, without any prior information of trends and functions, the method proposed in the paper can effectively recognize and evaluate the state of evolution of time series. Therefore, the method is a new method for time series analysis and can be considered as one of complements for the existing time series theory in use.

\section{Conclusions}

The identification method for evolution of time series with poor information is proposed by means of the grey system theory. Without any prior information of trends and functions, the method can effectively recognize and evaluate the state of evolution of time series, so that corresponding measures in a timely manner can be taken and serious accidents can be avoided.

The method is a new method for time series analysis and can be considered as one of complements for the existing time series theory in use.

\section{Acknowledgements}

The research is financed by the National Natural Science Foundation of China (Grant No. 51075123), the Natural Science Research Project of the Education Department of Henan Province (Grant No. 2010B460008), and the Doctoral Scientific Research Initiation Fund of Henan University of Science and Technology (Grant No. 09001318).

\section{References}

Ailliot, P., \& Monbet, V. (2012). Markov-switching autoregressive models for wind time series. Environmental Modelling and Software, 30, 92-101. http://dx.doi.org/10.1016/j.envsoft.2011.10.011 
Castro, N. C., \& Azevedo, P. J. (2012). Significant motifs in time series. Statistical Analysis and Data Mining, 5(1), 35-53. http://dx.doi.org/10.1002/sam.11134

Chen, C. H., Hong, T. P., \& Tseng, V. S. (2012). Fuzzy data mining for time-series data. Applied Soft Computing Journal, 12(1), 536-542.http://dx.doi.org/10.1016/j.asoc.2011.08.006

Coban, G., Büyüklü, A. H., \& Das, A. (2012). A linearization based non-iterative approach to measure the gaussian noise level for chaotic time series. Chaos, Solitons and Fractals, 45(3), 266-278. http://dx.doi.org/10.1016/j.chaos.2011.10.011

Das, D., \& Maitra, A. (2012). Time series predictor of Ku band rain attenuation over an Earth-space path at a tropical location. International Journal of Satellite Communications and Networking, 30(1), 19-28. http://dx.doi.org/10.1002/sat.992

Deng, J. L. (1989). Introduction to grey system theory. The Journal of Grey System, 1(1), 1-24.

Deng, J. L. (2002). Elements on Grey Theory. China, Wuhan: HUST Press. (in Chinese)

Eleni, P. T. (2008). Testing nonstationary time series for Gaussianity and linearity using the evolutionary bispectrum: An application to internet traffic data. Signal Processing, 88, 1355-1367. http://dx.doi.org/10.1016/j.sigpro.2007.12.011

Jiang, H., \& He, W. W. (2012). Grey relational grade in local support vector regression for financial time series $\begin{array}{llll}\text { prediction. } & \text { Expert }\end{array}$ http://dx.doi.org/10.1016/j.eswa.2011.07.100

Khvorostovsky, K. S. (2012). Merging and analysis of elevation time series over greenland ice sheet from satellite radar altimetry. IEEE Transactions on Geoscience and Remote Sensing, 50(1), 23-36. http://dx.doi.org/10.1109/TGRS.2011.2160071

Li, C. S., \& Hu, J. W. (2012). A new ARIMA-based neuro-fuzzy approach and swarm intelligence for time series forecasting. Engineering Applications of Artificial Intelligence, 25(2), 295-308. http://dx.doi.org/10.1016/j.engappai.2011.10.005

Palanikumar, K., Latha, B., Senthilkumar, V. S., \& Davim, J. Paulo. (2012). Analysis on drilling of glass fiber-reinforced polymer (GFRP) composites using grey relational analysis. Materials and Manufacturing Processes, 27(3), 297-305. http://dx.doi.org/10.1080/10426914.2011.577865

Paulin, C., \& Connely, K. B. (2005). Nonstationary hydrological time series forecasting using nonlinear dynamic methods. Journal of Hydrology, 307, 164-174. http://dx.doi.org/10.1016/j.jhydrol.2004.10.008

Sheng, C. Y., Zhao, J., Liu, Y., \& Wang, W. (2012). Prediction for noisy nonlinear time series by echo state network based on dual estimation. Neurocomputing, 82, 186-195. http://dx.doi.org/10.1016/j.neucom.2011.11.021

Sridhar, R., Narasimha Murthy, H. N., Pattar, N., Vishnu Mahesh, K. R., \& Krishna, M. (2012). Parametric study of twin screw extrusion for dispersing MMT in vinylester using orthogonal array technique and grey relational analysis. Composites Part B: Engineering, 43(2), 599-608. http://dx.doi.org/10.1016/j.compositesb.2011.08.025

Wen, K. L., You, M. L., \& Lee, B. Y. (2011). Apply grey relational grade and rough set theory for the factor weighting analysis in liver function. Journal of Convergence Information Technology, 6(9), 420-428. http://dx.doi.org/10.4156/jcit.vol6.issue9.48

Xia, X. T. (2012). Scientific view in grey system theory. Asian Social Science, 8(8), to be published.

Xia, X. T., \& Chen, J. F. (2011a). Fuzzy hypothesis testing and time series analysis of rolling bearing quality. Journal of Testing and Evaluation, 39(6), 1144-1151. http://dx.doi.org/10.1520/JTE103371

Xia, X. T., \& Li, J. H. (2011). Influence of vacuum on friction torque of rolling bearing for space application based on optimum grey relational space. The Journal of Grey System, 23(4), 327-334.

Xia, X. T., Chen, X. Y., Zhang, Y. Z., \& Yang, R. P. (2007). Rolling Bearing Test Analysis and Assessment with Poor Information. Science Press, Beijing, China. (in Chinese) 